\title{
Teaching More Than The Discipline: Modeling Leadership In The Classroom
}

\author{
Allen Jackson, Chadron State College, USA \\ Laura Gaudet, Chadron State College, USA \\ Larry McDaniel, Dakota State University, USA \\ Don Watt, Chadron State College, USA
}

\begin{abstract}
The educational process in higher education is much more than just the presentation of a discipline to a group of learners. Leaders in higher education are responsible to students to conduct themselves as educational leaders. Sensible leadership depends upon a variety of factors such as flexible behavior; an ability to identify specific behaviors needed at a particular time, and the ability to incorporate such behaviors at the appropriate time (Wilcox, 1997). A basic understanding of the supervisory behavioral continuum is important to the development of effective leadership skills. The continuum, adapted for use in the educational process, includes ten specific behaviors: listening, clarifying, encouraging, reflecting, presenting, problem-solving, negotiating, directing, standardizing, and reinforcing. Each behavior is clustered into the subgroups of directive, directive informational, collaborative, and nondirective. To be an effective leader one must have the ability to engage in all aspects of this continuum. To be effective in the college or university classroom, the instructor must have the knowledge about knowing when, why, and with whom to engage. Although one may have a preference or supervisory philosophy which indicates a personal preference to supervision and instruction, an understanding of the supervisory continuum is fundamental to the overall success of passing the role of leadership on to the next generation of learners.
\end{abstract}

Keywords: Sensible leadership, Supervisory behavioral continuum, Directive, Directive informational, Collaborative, Nondirective, Supervision

\section{WHAT WE NEED TO KNOW ABOUT EFFECTIVE LEADERSHIP IN THE CLASSROOM}

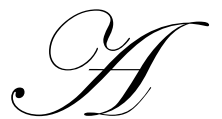

s educators we need to be aware of our overall effect on the learner. In Higher Education the educational process is much more than just presenting a specific discipline to a group of learners. We are responsible for the development of our countries future leaders. Leadership is much more then entitlement, it is an ongoing responsibility to the students we serve to present ourselves as leaders in education. Effective leadership comes from a variety of sources. Some people receive degrees which recognize them as trained professionals in the field of administration while others have acquired a high level confidence in their ability to work with and transform the lives of those they serve. Sensible leadership depends upon a variety of factors such as flexible behavior; an ability to identify specific behaviors needed at a particular time, and the ability to incorporate such behaviors at the appropriate time (Wilcox, 1997).

A basic understanding of a supervisory behavioral continuum, consisting of specific behaviors, is important in assisting one in developing the skills of effective leadership. There is a supervisory behavioral continuum which has been proven to play a vital role in the decision-making process. The continuum we have adapted for use in the educational process Includes ten specific behaviors; listening, clarifying, encouraging, reflecting, presenting, problem-solving, negotiating, directing, standardizing, and reinforcing. Each behavior is clustered into the subgroups of directive, directive informational, collaborative, and nondirective. 
To be an effective leader one must have the ability to engage in all aspects of this continuum which gives the instructor a method to deal effectively with everyday issues occurring in the classroom. As professionals we strive to offer learning experiences aimed at problem solving, and seeking workable solutions satisfactory to everyone. There are many skills involved in one's ability to lead, some taught, some acquired. As educators we need to know that groups function more effectively when leadership is shared in appropriate ways.

Most students are habituated to being in classes where the instructor assumes the dominant role of class leader. Students must also be given ownership and encouraged to assume an authoritative role in the decision making process. This can be best accomplished by providing encouragement and guidance in how to best take on different roles. When teachers neglect effective management practices and fail to provide leadership themselves, or invite students to take on leadership roles, scholars may often elect to engage in informal leadership roles in the classroom in an effort to unite the group. To initiate this type of skill training into the learning environment is an essential part of the overall educational experience.

To be more effective in the classroom the instructor must have the knowledge about knowing when, why, and with whom to engage. Although one may have a preference or supervisory philosophy which indicates a personal preference to supervision and instruction, an understanding of the supervisory continuum is fundamental to the overall success in passing the role of leadership on to the next generation of learners. Our presentation is in the appropriate use of this continuum.

\section{The Supervisory Behavioral Continuum}

Glickman, Gordon \& Ross-Gordon (2004) have presented criterion which identifies and expounds on the use of different approaches to supervision. As an instructor one encounters a variety of students possessing a wide range of skills and competencies. As the instructional leader one needs to develop an awareness of the capabilities of those with whom you work. Learning levels of ability vary for different areas, thus requiring diversity in ones approach to leadership (Glickman, Gordon \& Ross-Gordon, 2004). When the instructor initiates different forms of developmental instruction, the goal is to assess where the learner is and to supervise at the necessary level to develop a more self-reliant, reflective student (Glickman et al.).

A supervisory behavioral continuum is a necessary component which can be used to determine how interactions can be most effective between the teacher and scholar. This continuum may also play an important role in ones interaction with students. It offers an effective model incorporating different approaches which can be used in the decision-making process. The continuum gives the instructor a means to deal effectively with everyday issues, allowing one to come up with meaningful, workable solutions to unexpected problems (Directive Control Supervision, n.d.).

By understanding and employing this behavioral continuum, an instructor can motivate students to improve performance and provide different choices of action. In any organizational setting, it is necessary to match the supervisory strategies with different characteristics of the individual. By using strategies outlined within the supervisory behavioral continuum, educators can select the best approach or strategy for use with any given learner (Directive Control Supervision, n.d.).

Within this continuum, there are different sub groupings. The first being a "directive approach" which involves the instructor making direct statements and suggestions to the student about performance while offering encouragement. With this approach, feedback between the instructor and learner must occur. Decisions for the implementation of change are made by the supervising teacher who assumes responsibility for determining an appropriate plan of action (Stroot, Keil, Stedman, Lohr, Faust, Schincariol-Randall, Sullivan, Czerniak, Kuchcinski, Orel, \& Richter, 1998). For those who function at lower levels of development and need direct supervision this approach is commonly used (Glickman, Gordon, \& Ross-Gordon, 2004).

The "Directive Informational approach," the second sub component of the continuum is commonly used for younger students or those who are lacking experience, knowledge or confidence in making the transition from 
high school to the world of Academia (Glanz \& Sullivan, 2000). Key steps in this approach include identifying the problem and soliciting clear information while offering solutions to the problem, assessing alternatives, while requesting that the learner expound on different solutions. In the Directive Information approach, it is important to realize that learners are seeking information from the instructor who they feel can provide expert guidance. The instructor wants the learner to feel ownership in learning through sharing (Glanz, \& Sullivan).

Collaboration, another sub-component of the continuum, is a process involving group participation to initiate and sustain positive change. This gives the learner ownership in the class and builds on student confidence. Collaboration includes the process by which parties who see different aspects of a problem can explore the differences and search for solutions that go beyond their vision of what is possible. The instructor's decision is not the end-all in any deliberation. Students need to be encouraged to challenge ideologies, knowing that their input is heard and respected (Gray, 1989, p. 5, as cited by Borden \& Perkins, 1999).

Non-Directive supervision, the final sub-component in the continuum, is based on the assumption that individuals know best what changes need to occur. They are capable of thinking and acting on their own. The instructor is cognizant of the abilities of those under his or her tutelage and understands that learners can act in their own best interests. The educator's role is to direct the learner through the critical thinking and decision making process (Block, Korth, \& Lefebvre, n.d.). In Non-Directive supervision, the final sub-component in the continuum, the supervising roles changes, the instructor contributes little to the discussion unless asked. Any feedback from the instructor is intended to extend critical thinking; there is little influence in the actual design of the decision making process. In this case, the instructor is acting as a guide; asking leading questions while probing for in-depth thought (Block et al.).

\section{The Supervisory Behavioral Continuum: An Applied Approach To Learning}

Throughout the educational process it is our intent to encourage leadership by involving students in experiences aimed at developing independent thinkers with leadership skills. Dr. Larry McDaniel, an Associate Professor at Dakota State University, has developed an array of educational episodes where the use of the supervisory behavioral continuum plays a major role in the instructional process. Through an understanding of specific behaviors within the continuum, Dr. McDaniel discusses his methods of supervising students and provides examples of different supervisory strategies which will be employed in his classroom. After the behaviors, which will be employed throughout the lesson, are introduced and discussed with a population of learners, Dr. McDaniel demonstrates the behaviors specific to the "supervisory behavior continuum." Dr. McDaniel incorporates "direct informational supervision" and clarifies his expectations.

Dr. McDaniel's instructional methodologies are specific to the field of Physical Education. His use of supervisory strategies includes direct informational, collaborative, and nondirective supervision thus allowing students to participate in a variety of different learning experiences followed by different behaviors involving feedback. Learning episodes involving physical activity produce a variety of opportunities for Dr. McDaniel's students. His students are given opportunities to interact with groups of learners at different levels of human development while he capitalizes on the use of the supervisory behavioral continuum to guide his students toward a greater sense of self and the realization that they too are educational leaders.

In the educational settings developed by Dr. McDaniel, students assume the role of instructional leader and are in charge of the participants. Each learning experience involves, first, a focus on developing a safe environment and progresses to encouraging learners to engage in specific learning episodes. Dr. McDaniel's students are directed (direct informational supervision) to provide a learning or working climate which minimizes the fear of failure and injury (mental or physical). His students, through "collaborative leadership" become proficient in the four "D's", directing, demonstrating, providing practice drills, and discussing progress. With this process, Dr. McDaniel's students are engaged in the use of the "supervisory behavioral continuum"!

Physical activity skills are presented through demonstrations by the student in charge (Dr. McDaniel's student) or a participant accompanied with "directions" and "clarifications" (direct informational supervision) for 
correct performance through appropriate feedback (critical cues to perform the skill). While participants practice the skill, the student leader moves along the outer perimeter of the activity "observing" and assisting learners in problem solving and performing the skill correctly. Throughout the lesson, the student instructor "reinforces" the desired behavior and performance of the skill pattern. The student leader asks participants questions related to the skill and then "listens" to the answers provided by the participants. This allows the student leader information which may result in quality feedback and encourages and motivates participants to improve performance.

After the lesson, Dr. McDaniel "reflects" on the performance of the participants which allows for an objective evaluation of the performance of the student leader. Dr. McDaniel may offer suggestions about how to improve the lesson and whether or not pre-determined learning objective were realized. Dr. McDaniel encourages student leaders to offer extrinsic rewards for good behavior by allowing participants time during the next lesson to become involved in a favorite activity. Dr. McDaniel also provides on occasion, an unsuspected problem such as an injury or a behavior problem. This activity provides students opportunities to manage unexpected events. A typical lab would consist of other trainees (observers) and elementary or high school students. It provides an outstanding opportunity for Dr. McDaniel's students to develop leadership skills. These learning activities are often videotaped. This allows the instructor to use the learning experience as a teaching tool and an opportunity for timely and appropriate feedback. Video, a powerful learning tool for prospective leaders, provides the opportunity for the learners to see themselves as others see them.

Another colleague who uses supervisory strategies reminiscent of the Glickman, et al. (2004) continuum is Mr. Don Watt, Associate Professor for the Department of Health, Physical Education, and Recreation at Chadron State College. Mr. Watt incorporates direct informational supervision strategies in his face-to-face lectures to transfer information to the learner. He effectively employs behaviors in a specific order to improve longtime memory among his students. His supervisory behaviors include presenting, directing, clarifying, encouraging, problem-solving reflecting, and reinforcing. By sequencing these behaviors, Mr. Watt clearly contributes to the learning experience. After presenting materials and expectations, Mr. Watt's teaching strategies focus change. Mr. Watt feels it is extremely important for students to have a high level of confidence and readiness to assume leadership roles. Students must realize that the decisions they make may impact a student's life forever.

Mr. Watt fully recognizes the value of collaboration and nondirective supervision in building self-reliant learners. He instructs Sports Training and Caring for Athletic Injuries at Chadron State College. His students need to develop high levels of confidence when making decisions involving the welfare of others. Through Mr. Watt's efforts and the use of an array of strategies when presenting learning episodes, his students are allowed opportunities to act in the decision making process. When Mr. Watt has commenced the educational experiences of his students, they are reliable individuals who possess the tools necessary to enable them to assume leadership roles within their chosen profession.

\section{CONCLUSION}

Both Dr. McDaniel and Mr. Don Watt are very conscious and competent in the use of the "supervisory behavioral continuum" and employ these strategies in lesson planning. The continuum consists of a number of different supervisory behaviors which play a major role in the decision-making process when interacting with a group of learners. Dr. McDaniel uses behaviors such as observing, listening, reflecting, standardizing, and clarifying, with supervising strategies involving collaboration and non-direct supervision to guide student leaders. These leaders employs direct, direct informational and collaboration when working with groups of younger learners. Student learner actions include the full spectrum of behaviors identified in the supervisory behavior continuum. These young leaders are also given freedom to engage in other forms of supervision not identified in the Glickman et al. (2004) continuum.

To be an effective leader, one must have the ability to engage in all aspects of this continuum which gives the educator a method for dealing effectively with everyday issues that may occur within the classroom setting and to come up with workable solutions that contribute to student learning (Block, Korth, \& Lefebvre, n.d.). Supervisory skills are an essential part of effective instruction by providing the mentor with knowledge about knowing when and 
with whom to engage appropriate behaviors included in this continuum. Although one may have a preference or leadership philosophy which indicates a personal preference to supervision, the supervisory continuum is vital to the overall success of any organization and may be employed in the classroom to begin building leadership skills among students.

\section{AUTHOR INFORMATION}

Allen Jackson, M. Ed. is an Assistant Professor at Chadron State College, in Chadron, Nebraska. He has taught in the Department of Health, Physical Education and Recreation (HPER) for five years. He teaches course in Personal Health and Wellness, Introduction to Recreation, Biomechanics of Sports, Community and Environmental Health and several activities courses. He is a doctoral student at Northcentral University in Prescott Valley, Arizona and is about to begin the dissertation phase of his program.

Laura Gaudet, Ph. D. is a Professor of Psychology at Chadron State College, in Chadron, Nebraska. She has taught in the Department of Counseling, Psychology, and Social Work for ten years and has served as the Chairperson of the department since 2003. As she has degrees in both Psychology and Counseling, she teaches both undergraduate Psychology and graduate Counseling courses in Multicultural Counseling, Consultation \& Program Development, School Counseling, Family Counseling, Advanced Developmental Psychology, Career and Lifestyle Development, Ethical and Legal Issues, Child Psychology, Developmental Psychology, Abnormal Psychology, and General Psychology. She primarily develops and teaches courses online.

Larry McDaniel, Ed. D. is an Associate Professor at Dakota State University in Madison, South Dakota. He has taught at Dakota State University for five years after teaching at Chadron State College for 4 years. He teaches in the Department of Human Performance and teaches both undergraduate and graduate students in the College of Education, SDU.

Don Watt, M. S. is a Professor of Physical Education at Chadron State College, Chadorn, Nebraska. He serves the college as Athletic Trainer and teaches Prevention and Care of Athletic Injuries and Safety and First Aid. He is involved in athletic prevention and intervention for all sporting activities.

\section{REFERENCES}

1. $\quad$ Block, M., Korth, S., \& Lefebvre, M. (n.d.). Examining instructional supervision. Retrieved August 5 2007, from http://www.msu.edu/user/lefebvr6/synthesis1.html

2. Borden, L., \& Perkins, D. (1999). Assessing your collaboration: A self evaluation tool. Journal of Extension. 37, 2. Retrieved August 6, 2007, from http://www.joe.org/joe/1999april/tt1.html

3. Directive Control Supervision (n.d.). Retrieved August 4, 2007, from http://www.msu.edu/user/blockmat/finalgrouppaper2.html

4. Glanz, J., \& Sullivan, S. (2000). Supervision in Practice: 3 Steps to Improving Teaching and Learning. Retrieved August 5, 2007, from http://books.google.com/books?q=The+directive+informational+approach+\&ots=fFOfaFYg9P\&sa=X\&oi= print\&ct=title

5. Glickman, C., Gordon, S., \& Ross-Gordon, J. (2004). SuperVision and Instructional Leadership: A Developmental Approach. Boston: Pearson.

6. Stroot, S., Keil, V., Stedman, P., Lohr, L., Faust, R., Schincariol-Randall, L., Sullivan, A., Czerniak, G., Kuchcinski, J., Orel, N., \& Richter, M. (1998). Peer assistance and review guidebook. Columbus, OH: Ohio Department of Education. Retrieved August 5, 2007, from http://www.utoledo.edu/colleges/education/par/Conferencing.html

7. Wilcox, S., (1997). Leadership in the classroom. Instructional Development Centre, Queen's University. Retrieved January 14, 2008, from http://ddi.cs.unipotsdam.de/Lehre/WissArbeitenHinweise/teachingassistant/hand/leader.html 


\section{NOTES}

